\title{
DHA brain uptake and APOE4 status: a PET study with $\left[1-{ }^{11} \mathrm{C}\right]-\mathrm{DHA}$
}

\author{
Hussein N. Yassine ${ }^{1 *}$, Etienne Croteau ${ }^{2}$, Varun Rawat ${ }^{1}$, Joseph R. Hibbeln ${ }^{3}$, Stanley I. Rapoport ${ }^{4}$,
} Stephen C. Cunnane ${ }^{2}$ and John C. Umhau ${ }^{3,5}$

\begin{abstract}
Background: The apolipoprotein E $\varepsilon 4$ (APOE4) allele is the strongest genetic risk factor identified for developing Alzheimer's disease (AD). Among brain lipids, alteration in the $\omega-3$ polyunsaturated fatty acid docosahexaenoic acid (DHA) homeostasis is implicated in AD pathogenesis. APOE4 may influence both brain DHA metabolism and cognitive outcomes.

Methods: Using positron emission tomography, regional incorporation coefficients $\left(k^{*}\right)$, rates of DHA incorporation from plasma into the brain using $\left[1-{ }^{11} \mathrm{C}\right]-\mathrm{DHA}\left(\mathrm{J}_{\mathrm{in}}\right)$, and regional cerebral blood flow using $\left[{ }^{15} \mathrm{O}\right]$-water were measured in 22 middle-aged healthy adults (mean age 35 years, range 19-65 years). Data were partially volume error-corrected for brain atrophy. APOE4 phenotype was determined by protein expression, and unesterified DHA concentrations were quantified in plasma. An exploratory post hoc analysis of the effect of APOE4 on DHA brain kinetics was performed.
\end{abstract}

Results: The mean global gray matter DHA incorporation coefficient, $k^{*}$, was significantly higher (16\%) among APOE4 carriers $(n=9)$ than among noncarriers $(n=13, p=0.046)$. Higher DHA incorporation coefficients were observed in several brain regions, particularly in the entorhinal subregion, an area affected early in AD pathogenesis. Cerebral blood flow, unesterified plasma DHA, and whole brain DHA incorporation rate $\left(J_{\text {in }}\right)$ did not differ significantly between the APOE groups.

Conclusions: Our findings suggest an increase in the DHA incorporation coefficient in several brain regions in APOE4 carriers. These findings may contribute to understanding how APOE4 genotypes affect AD risk.

Keywords: APOE, Alzheimer's disease, DHA, PET

\section{Background}

Apolipoprotein E \&4 (APOE4) genotype is the strongest genetic risk factor for late-onset or sporadic Alzheimer's disease (AD). APOE proteins, the product of the APOE gene, have isoform-specific functions. For example, APOE's affinity for the low-density lipoprotein receptor is known to differ between isoforms (APOE4 > APOE3 > APOE2) [1]. These differences have implications for the metabolism of APOE lipoprotein particles and the amount of lipid carried by APOE. In the brain, APOE forms high-density lipoprotein particles and participates in exchange of lipids between glial cells and neurons [2]. Clinical and animal studies indicate that brain APOE

\footnotetext{
* Correspondence: hyassine@usc.edu

${ }^{1}$ Department of Medicine, University of Southern California, 2250 Alcazar

Street, Room 210, Los Angeles, CA 90033, USA

Full list of author information is available at the end of the article
}

particle size and number differ by APOE genotype [3-5]. In plasma, APOE4 is catabolized faster with a plasma residence time of approximately half that of APOE3 [6].

Among brain lipids, the $\omega-3$ polyunsaturated fatty acid (PUFA) docosahexaenoic acid (DHA, 22:6 $\omega-3$ ) may be of particular importance in AD pathogenesis. DHA forms up to $40 \%$ of fatty acids in certain gray matter lipids and is concentrated at synapses, where it plays a role in synaptic plasticity [7]. In embryonic neuronal cultures, DHA supplementation promotes neurite growth and synaptic protein expression [8]. Severe long-term dietary deficiency of DHA leads to learning impairment in animal models [9]. The brain also requires DHA for maintenance of neuronal membranes, production and clearance of $\beta$-amyloid 42, modulation of inflammation $[10,11]$, and cerebrovascular health [12]. We previously reported a direct association between lower serum DHA 
levels and greater cerebral amyloidosis in cognitively healthy older adults [13]. The lowest quartile of serum DHA was associated with significantly greater cerebral amyloid deposition, smaller entorhinal and hippocampal volumes, and worse nonverbal memory scores [13].

DHA's incorporation into the brain can be assessed by positron emission tomography (PET) following intravenous infusion of carbon-11 ([1- $\left.\left.{ }^{11} \mathrm{C}\right]\right)$-DHA using the incorporation coefficient $k^{*}$ [14]. $k^{*}$ represents multiple steps, including DHA diffusion from plasma to brain cells, intracellular DHA acylation to DHA-CoA by an acylcoenzyme A (acyl-CoA) synthetase, and DHA transfer from DHA-CoA to membrane lysophospholipids by an acyltransferase [15]. $k^{*}$ is independent of changes in regional cerebral blood flow (rCBF). For example, rCBF can be doubled using $\mathrm{CO}_{2}$ inhalation without changing $k^{*}$ [16]. The net rate of DHA incorporation from plasma $\left(J_{\text {in }}\right)$ is the product of unesterified plasma DHA times $k^{*}$. At steady state, $J_{\text {in }}$ is equivalent to the net loss of DHA from the brain $\left(J_{\text {out }}\right)$. Chronic dietary $\omega-3$ PUFA deprivation leads to increased $k^{*}$ in the face of a 40-fold reduction in the rate of DHA loss $\left(J_{\text {out }}\right)$ from the brain [17].

$A P O E$ genotype may influence the metabolism of DHA in the brain or its delivery to the brain, although brain DHA delivery may not directly depend on peripheral lipoproteins [18]. In humans, whole body DHA halflife was lower in APOE4 carriers than in noncarriers, which was attributed to greater liver oxidation of DHA [19]. Brain DHA levels were lower in older but not younger $A P O E 4$ targeted replacement (TR) mice than in age-matched $A P O E 2$ TR mice [20]. We found lower cerebrospinal fluid (CSF) DHA levels in older APOE4 carriers with mild AD after 18 months of DHA supplementation than in APOE4 noncarriers [21]. The goal of the present study was to explore the effect of APOE4 on $\left[1-{ }^{11} \mathrm{C}\right]$-DHA brain kinetics in a group of 22 healthy adults using PET.

\section{Methods}

Participants

We obtained plasma samples from 22 healthy control subjects between 19 and 65 years of age to assess APOE4 expression and APOE plasma levels. These subjects were recruited from the Bethesda, MD, USA, area [22]. The present report describes results from the control arm only of an alcohol withdrawal study. Participants were nonsmokers and reported no medication, drug, or alcohol use for at least 2 weeks prior to the PET scan. All participants underwent an extensive history and physical examination with laboratory tests to ensure that they were free of significant medical problems and had no history of neurological or psychiatric disorders. Three days preceding the PET scan, participants were instructed to avoid foods high in $\omega$-3 PUFAs (e.g., seafood). The Diet History Questionnaire was used to assess dietary habits 12 months preceding the study [23].

\section{PET imaging}

The PET protocol involved first injecting a bolus of $\left[{ }^{15} \mathrm{O}\right]$-water to image rCBF. PET scans were acquired at approximately 11:00 a.m. following $24 \mathrm{~h}$ on a standardized low-DHA diet and an overnight fast. Blood was collected three times during the scan to quantify plasma unesterified fatty acid concentrations and tracer radioactivity. Fifteen minutes following the injection of $\left[{ }^{15} \mathrm{O}\right]$-water, $1118 \mathrm{MBq}$ of $\left[1-{ }^{11} \mathrm{C}\right]$-DHA was infused intravenously for 3 minutes at a constant rate (Harvard Infusion Pump, South Natick, MA, USA). Because of the high specific activity of $\left[1-{ }^{11} \mathrm{C}\right]$-DHA, less than $0.06 \mathrm{mmol}$ of unlabeled DHA was infused into a subject, so there was no significant pharmacological or tracee effect of the dose of the tracer itself. Serial dynamic three-dimensional scans were acquired during the hour following the start of the infusion. Arterial samples $(2-5 \mathrm{ml})$ were obtained at fixed times to determine radioactivity in whole blood and plasma.

\section{Input function}

To rapidly assay plasma $\left[1-{ }^{11} \mathrm{C}\right]$-DHA during a PET scan, a solid-phase extraction procedure to separate unesterified $\left[1-{ }^{11} \mathrm{C}\right]$-DHA from remaining plasma radioactivity was used. From plasma samples collected at $0,3,7,10,15,20,40$, and 60 minutes after infusion of $\left[1-{ }^{11} \mathrm{C}\right]-\mathrm{DHA}$, total lipids were extracted into chloroform:methanol (1:1) as previously described [24].

\section{Coregistration of PET scans to brain anatomy}

Magnetic resonance imaging (MRI) scans of the brain were obtained with a 1.5-Tesla Horizon scanner (GE Medical Systems, Milwaukee, WI, USA). This produced T1-weighted volumetric spoiled gradient MRI scans for superimposition onto the PET images and to register both $\mathrm{rCBF}$ images from the $\left[{ }^{15} \mathrm{O}\right]$-water scans and $\left[1-{ }^{11} \mathrm{C}\right]$-DHA parametric images. Appropriate coregistration of the PET images onto the MRI studies was visually verified for each participant. Because of the poor spatial resolution of a PET scan, underestimation of higher radioactivity can occur in gray matter regions. To provide the most accurate measure of radioactivity in specific gray matter regions, partial volume error (PVE) was corrected. PVE correction is particularly important when studying disorders associated with cerebral atrophy, such as aging, cognitive decline, and AD. It provides a better measure of actual tissue metabolism or blood flow free of effects of CSF, and it corrects for loss (spill-out) of the 
radioactive signal to adjacent tissue and for spill-in of signal from adjacent tissue.

\section{Regions of interest}

Following injection of $\left[1-{ }^{11} \mathrm{C}\right]-\mathrm{DHA}, k^{*}(\mu \mathrm{l} / \mathrm{minute} / \mathrm{ml})$ was calculated from the PVE-corrected PET brain images using a one-tissue compartment model as described previously [24]. Two approaches were used to perform the image analysis. First, regions of interest (ROIs) were drawn manually on individual MRI scans on six continuous axial MRI slices at the National Institutes of Health PET center [24]. PVE-corrected values of $k^{*}$ and rCBF were obtained for all regions from PET images by limiting averaging to voxels identified as gray matter by the segmentation procedure. Second, T1-weighted MRI FreeSurfer segmentation was used for the kinetic analysis of ROIs of the $\left[1-{ }^{11} \mathrm{C}\right]$-DHA cerebral dynamic acquisitions from 21 of the 22 participants at the University of Sherbrooke, Sherbrooke, QC, Canada. Figure 1 presents an illustration of $\left[1-{ }^{11} \mathrm{C}\right]$-DHA $k^{*}$ focused in the entorhinal cortex area of one of the participants.

\section{APOE phenotyping and ApoE plasma levels}

APOE4 phenotype was obtained by Western blotting of plasma samples using a previously validated APOE4specific antibody (8941S; Cell Signaling Technology, Danvers, MA, USA). The validity of the antibody was confirmed using samples of known $A P O E$ genotype. APOE4 status was defined by visible APOE4 bands after
Western blotting of plasma samples. APOE plasma levels were measured using an in-house enzyme-linked immunosorbent assay with inter- and intraassay coefficients of variation $<10 \%[25]$.

\section{Data analysis}

Data are presented as means with SDs. The two APOE groups were compared using an independent $t$ test or linear regression modeling to adjust for covariates. Age and sex were added to the linear model as covariates with $k^{*}$ as the dependent variable and $A P O E$ group as the independent variable. The variables were correlated using Pearson's correlations for normally distributed data or Spearman's correlations for nonnormally distributed data. Within the brain regions, we focused on the medial temporal lobe subregions, given their significance in $\mathrm{AD}$, with FreeSurfer segmentation to assess ROI $\left[1-{ }^{11} \mathrm{C}\right]$ DHA kinetics. $p \leq 0.05$ was considered a significant difference.

\section{Results \\ Participant characteristics}

Our study sample included 13 APOE4-negative and 9 APOE4-positive participants, based on the detection of APOE4 proteins in plasma by Western blotting. The participants were mostly middle-aged white individuals who were not obese and were without diabetes or dyslipidemia. The participants' characteristics did not differ by

\section{T1-weighted MRI}
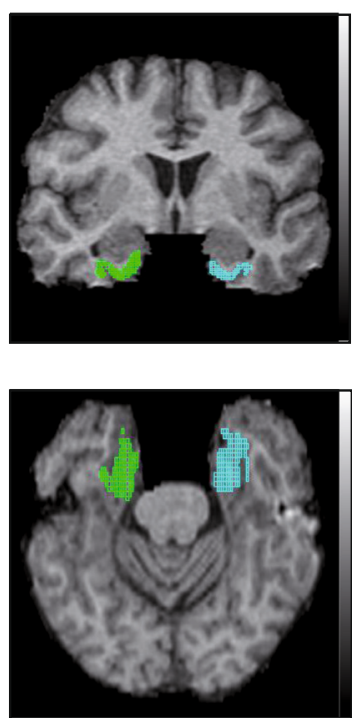

$\left[1-{ }^{11} \mathrm{C}\right]-$ Docosahexaenoic acid

Coronal
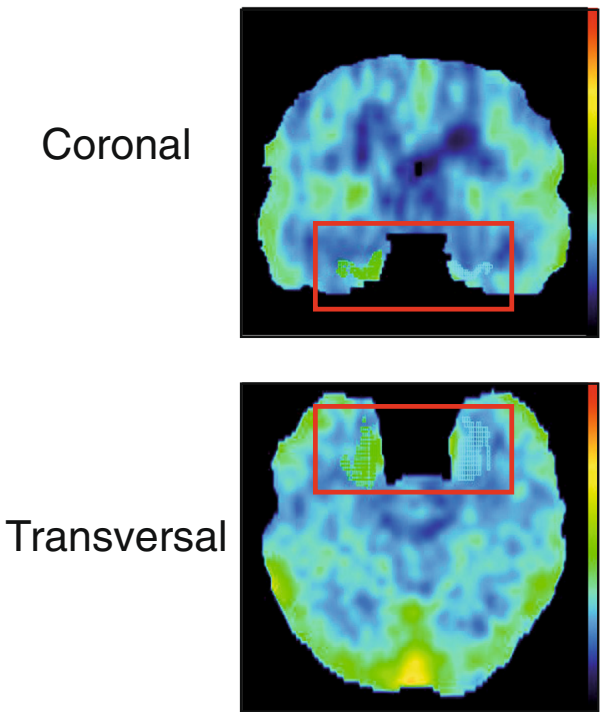

Fig. 1 FreeSurfer segmentation (green = right hemisphere, blue= left hemisphere) of the entorhinal region of interest superimposed on a sum image (60 minutes) of $\left[{ }^{11} \mathrm{C}\right]$-docosahexaenoic acid $\left(\left[1-{ }^{11} \mathrm{C}\right]-\mathrm{DHA}\right)$ and T1-weighted magnetic resonance imaging scans of one participant. DHA incoporation coefficient $k^{*}$ in the entorhinal cortex is illustrated in the red rectangles 
APOE genotype. Additional characteristics and biochemical measurements are presented in Table 1.

\section{DHA incorporation coefficient, $k^{*}$}

The mean global gray matter $k^{*}$ was $16 \%$ higher in APOE4 carriers than in noncarriers $(p=0.04)$ (Fig. 2a). $k^{*}$ was significantly higher in several gray matter subregions (Table 2), but it did not differ in the white matter by $A P O E$ subgroup. Age did not correlate with $k^{*}(r=-0.006, p=$ $0.9)$, but only 4 of the 23 participants were older than 50 years of age. BMI $(r=-0.04, p=0.89)$ and sex $(p=0.8)$ also did not correlate with $k^{*}$. Including age $(p=0.12)$ or sex $(p=0.1)$ attenuated the effect of $A P O E$ on global gray matter $k^{*}$. The $k^{*}$ in the medial temporal lobe was $17 \%$ higher in APOE4 carriers than in noncarriers $(p=0.035)$ (Fig. 2b). On the basis of FreeSurfer segmentation for the kinetic analysis of ROI of the $\left[1-{ }^{11} \mathrm{C}\right]-\mathrm{DHA}$ dynamic acquisitions in the medial temporal lobe, the most pronounced difference in $k^{*}$ was observed in the right entorhinal region (34\% greater in APOE4 carriers than in noncarriers; $p=0.05$ ) (Table 3). A significant inverse correlation was observed between $k^{*}$ and blood volume in the medial temporal lobe $(r=-0.42, p=0.05)$.

\section{DHA incorporation rate $\left(U_{\text {in }}\right)$}

The brain incorporation rate of DHA $\left(J_{\text {in }}\right)$ was calculated using the global gray matter (average of 19 gray matter regions) value for $k^{*}$ before PVE correction multiplied by plasma unlabeled unesterified DHA concentrations. Unesterified plasma DHA concentrations were not different between $A P O E 4$ noncarriers and $A P O E 4$ carriers $(2.0 \pm 1.1$ vs. $2.2 \pm 1.5 \mathrm{nmol} / \mathrm{ml}$, respectively; $p=0.76)$.
Among APOE4 noncarriers and carriers, gray matter $J_{\text {in }}$ was $5.0 \pm 3.3$ vs. $6.3 \pm 4.5 \mu \mathrm{mol} /$ day $/ \mathrm{g}$, respectively $(p=$ 0.49). With a mean whole brain volume of $1242 \mathrm{ml}$ (calculated by MRI), this DHA incorporation rate was equivalent to a daily whole brain DHA incorporation rate of $3.8 \pm 2.5 \mathrm{mg} /$ day for APOE4 noncarriers and $4.6 \pm$ $3.3 \mathrm{mg} /$ day for APOE4 carriers $(p=0.5)$. Gray matter $J_{\text {in }}$ was not significantly different between the $A P O E$ groups, mainly because plasma DHA concentration had large variance in the two groups.

\section{Cerebral blood flow}

Neither mean overall gray matter nor medial temporal lobe CBF differed significantly between the $A P O E$ subgroups (global gray matter CBF 69.9 (16.7) $\mathrm{ml} \times 100 \mathrm{~g}^{-1} \times$ minute $^{-1}$ in noncarriers vs. $71.4(11.8) \mathrm{ml} \times 100 \mathrm{~g}^{-1} \times$ minute $^{-1}$ in APOE4 carriers; $p=0.8$ ). Mean gray matter and medial temporal lobe $k^{*}$ did not correlate with the respective rCBF (data not shown).

\section{Discussion}

In this exploratory post hoc analysis, we identified a significantly greater mean global gray matter DHA incorporation coefficient $\left(k^{*}\right)$ in APOE4 carriers compared with noncarriers. This difference was present in several brain regions, including the posterior cingulate cortex and the medial temporal lobe. Within the medial temporal lobe, higher DHA $k^{*}$ was prominent in the entorhinal cortex area. The simplest explanation for the significantly higher values of $k^{*}$ in $A P O E 4$ carriers is an increased incorporation by the brain from circulating unesterified DHA, replacing DHA that is either metabolized to

Table 1 Participant characteristics

\begin{tabular}{llll}
\hline Group & APOE4 noncarriers $(n=13)$ & APOE4 carriers $(n=9)$ & $p$ Value \\
\hline Female/male sex & $8 / 5$ & $2 / 7$ & $4 / 5$ \\
White/nonwhite race & $8 / 5$ & $32.1(10.7)$ & 0.07 \\
Age, years & $37.1(15.7)$ & $85.7(20.4)$ & 0.93 \\
Weight, $\mathrm{kg}$ & $77.1(15.7)$ & $27.1(5.0)$ & 0.39 \\
BMl, $\mathrm{kg} / \mathrm{m}^{2}$ & $26.2(4.2)$ & $118.4(14.7)$ & 0.30 \\
Systolic blood pressure, $\mathrm{mmHg}$ & $111(9.2)$ & $62.8(7.2)$ & 0.64 \\
Diastolic blood pressure, $\mathrm{mmHg}$ & $60.3(10.6)$ & $90(9.5)$ & 0.35 \\
Fasting glucose, mg/dl & $94(9.3)$ & $168.1(31.1)$ & 0.61 \\
Total cholesterol, $\mathrm{mg} / \mathrm{dl}$ & $162(42.9)$ & $53.7(11.9)$ & 0.37 \\
HDL-C, mg/dl & $49.8(17.7)$ & $101(28.8)$ & 0.70 \\
LDL-C, mg/dl & $98.3(33.4)$ & $130(120)$ & 0.54 \\
Estimated DHA intake based on DHQ, mg/day & $40(41)$ & $1232(62)$ & 0.84 \\
Brain volume, $\mathrm{ml}$ & $1246(150)$ & $10.7(6.1)$ & 0.1 \\
Plasma APOE levels, $\mu \mathrm{g} / \mathrm{ml}$ & $15.8(5.7)$ & 0.76 \\
\hline
\end{tabular}

Abbreviations: APOE Apolipoprotein E, APOE4 Apolipoprotein E $\varepsilon 4, B M I$ Body mass index, DHA Docosahexaenoic acid, DHQ Diet History Questionnaire, HDL-C Highdensity lipoprotein cholesterol, LDL-C Low-density lipoprotein cholesterol

Values are presented as mean (SD). Groups were compared using an independent $t$ test 

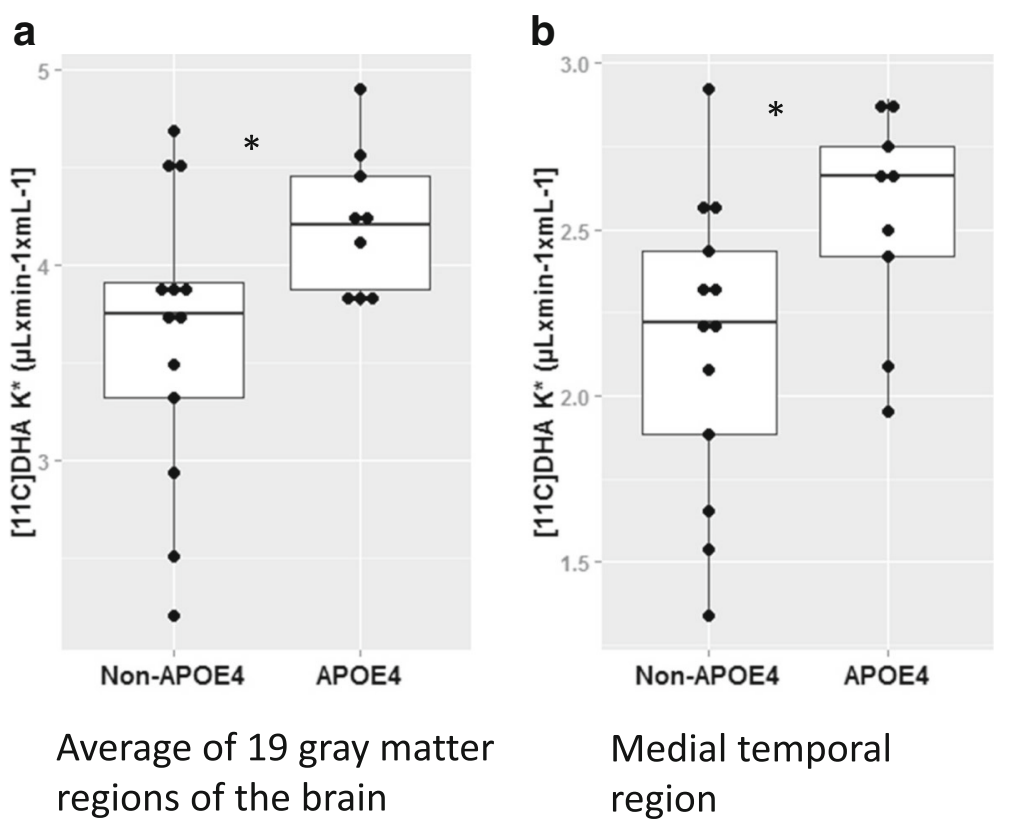

Fig. 2 Mean global brain (a) and medial temporal lobe (b) docosahexaenoic acid (DHA) incorporation coefficient $k^{*}$ by apolipoprotein $E$ gene $(A P O E)$ subgroups. Significantly greater DHA uptake was observed in APOE4 carriers than in noncarriers $\left({ }^{*} p \leq 0.05\right)$

Table 2 Regional DHA $k^{*}$ by APOE subgroup $\left(\mu \mathrm{l} \quad\right.$ minute $\left.^{-1} \quad \mathrm{ml}^{-1}\right)$

\begin{tabular}{|c|c|c|c|c|}
\hline Regions & APOE4 noncarriers $(n=13)$ & APOE4 carriers $(n=9)$ & $p$ Value & Adjusted $p$ value $^{a}$ \\
\hline Orbitofrontal & $4.84(1.25)$ & $5.20(0.59)$ & 0.42 & 0.79 \\
\hline Prefrontal & $3.81(0.76)$ & $4.37(0.56)$ & 0.07 & 0.12 \\
\hline Premotor & $3.86(0.73)$ & $4.65(0.51)$ & 0.01 & 0.057 \\
\hline Anterior cingulate & $2.76(0.55)$ & $3.27(0.31)$ & 0.02 & 0.088 \\
\hline Inferior temporal & $3.56(0.87)$ & $3.96(0.37)$ & 0.21 & 0.56 \\
\hline Middle temporal & $3.72(0.83)$ & $4.11(0.39)$ & 0.21 & 0.57 \\
\hline Superior temporal & $3.42(0.88)$ & $3.69(0.50)$ & 0.41 & 0.87 \\
\hline Medial temporal & $2.16(0.45)$ & $2.53(0.33)$ & 0.046 & 0.28 \\
\hline Sensorimotor & $3.95(0.84)$ & $4.78(0.52)$ & 0.016 & 0.12 \\
\hline Inferior parietal & $3.89(0.87)$ & $4.42(0.46)$ & 0.26 & 0.40 \\
\hline Superior parietal & $4.38(1.09)$ & $4.81(0.35)$ & 0.26 & 0.59 \\
\hline Medial parietal & $3.55(0.88)$ & $4.35(0.38)$ & 0.018 & 0.087 \\
\hline Posterior cingulate & $3.09(0.71)$ & $4.00(0.34)$ & 0.002 & 0.02 \\
\hline Occipital association & $3.98(0.86)$ & $4.81(0.47)$ & 0.016 & 0.12 \\
\hline Calcarine & $4.41(1.01)$ & $5.07(0.64)$ & 0.098 & 0.35 \\
\hline Thalamus & $3.90(0.99)$ & $4.62(0.43)$ & 0.053 & 0.06 \\
\hline Striatum & $3.57(0.95)$ & $4.16(0.84)$ & 0.149 & 0.11 \\
\hline Cerebellar hemisphere & $3.30(0.82)$ & $3.91(0.53)$ & 0.141 & 0.29 \\
\hline Vermis & $2.97(0.81)$ & $3.60(0.50)$ & 0.051 & 0.046 \\
\hline Pure white matter & $1.09(0.41)$ & $1.26(0.16)$ & 0.25 & 0.21 \\
\hline Average gray matter & $3.64(0.75)$ & $4.23(0.37)$ & 0.04 & 0.19 \\
\hline
\end{tabular}

\section{APOE4 Apolipoprotein E $\varepsilon 4$}

Data are presented as mean (SD). Docosahexaenoic acid $k^{*}$ values were partial volume error-corrected. Groups were compared using a linear regression model. Significantly differences $(p<0.05)$ by APOE group are shown in bold type

adjusted to age and sex 
Table 3 Docosahexaenoic acid incorporation coefficient $\left(k^{*}, \mu l \quad\right.$ minute $\left.^{-1} \mathrm{ml}^{-1}\right)$ in medial temporal lobe subregions according to APOE genotype

\begin{tabular}{llll}
\hline & APOE4 noncarriers $(n=12)$ & APOE4 carriers $(n=9)$ & $p$ Value \\
\hline Hippocampus & $2.69(0.73)$ & $2.86(0.35)$ & 0.43 \\
Left & $2.8(0.80)$ & $2.9(0.4)$ & 0.60 \\
Right & $2.6(0.70)$ & $2.8(0.4)$ & 0.47 \\
Entorhinal cortex & $2.77(0.10)$ & $3.57(0.67)$ & 0.056 \\
Left & $2.6(1.10)$ & $3.2(0.5)$ & 0.16 \\
Right & $2.9(1.0)$ & $3.9(1.2)$ & 0.05 \\
\hline
\end{tabular}

APOE Apolipoprotein E; APOE4 Apolipoprotein E $\varepsilon 4$

Data are presented as mean (SD). Groups were compared using an independent $t$ test

bioactive products or lost to degradation. Given the small sample size and the exploratory nature of this study, these results are proof of concept and require additional validation.

Vandal et al. reported reduced brain DHA levels in older but not younger APOE4 mice compared with agematched APOE2 TR mice [20]. We recently reported lower CSF DHA levels in older APOE4 carriers with AD after 18 months of DHA supplementation than in $A P O E 4$ noncarriers [21]. It is possible that the increased $k^{*}$ represents a compensatory mechanism in younger $A P O E 4$ carriers to cope with increased brain DHA loss and to maintain brain DHA levels. This mechanism might become impaired with aging, predisposing older $A P O E 4$ carriers to reduced brain DHA levels and increasing the risk for cognitive decline.

It is not possible on the basis of PET images to distinguish the exact metabolite explaining the higher incorporation of DHA in the brain. The equation for calculating $k^{*}$ assumes that all $\left[1-{ }^{11} \mathrm{C}\right]-\mathrm{DHA}$ is irreversibly trapped in the brain and that no radioactive metabolite other than $\left[{ }^{11} \mathrm{C}\right]-\mathrm{CO}_{2}$ crosses the blood-brain barrier (BBB). This could result from more efficient transport of unesterified DHA across the $\mathrm{BBB}$, increased activation of DHA to DHA-CoA by an acyl-CoA synthetase, greater esterification into brain membrane lipid by an acyltransferase, or decreased hydrolysis by phospholipase $\mathrm{A}_{2}\left(\mathrm{PLA}_{2}\right)$ [26]. Any one of these steps could be influenced by $A P O E$ genotype.

Several factors can alter $k^{*}$. For example, $k^{*}$ was decreased in mice genetically lacking calcium-independent $\mathrm{PLA}_{2} \beta$ VIA [27], but it was increased when plasma and brain DHA concentrations were reduced by chronic dietary $\omega-3$ PUFA deprivation in rats [17] or in subjects with chronic alcoholism during acute withdrawal of alcohol [22]. Moreover, the DHA transport coefficient was decreased with long-term high-DHA dietary consumption [28]. Therefore, differences in habitual intake of DHA may indirectly affect $k^{*}$. To reduce variation in DHA intake in the present study, participants were instructed to avoid foods high in $\omega-3$ PUFAs (e.g., seafood) 3 days preceding the PET scan, and they were limited to one caffeinated beverage per day. Beginning $24 \mathrm{~h}$ before the PET scan, they consumed standardized meals; in addition, they did not eat for $12 \mathrm{~h}$ prior to the scan. The differences in plasma DHA levels or DHA dietary intake were not significant by group.

The lower value of $k^{*}$ in the medial temporal cortex is consistent with previous reports for $\left[1-{ }^{11} \mathrm{C}\right]$ - arachidonic acid and with values for $\operatorname{rCBF}[29,30]$. The data likely reflect the unique architecture of this region, although there is some effect of the PVE correction [24]. We previously reported that lower plasma levels of DHA were significantly associated with lower entorhinal brain volumes in older cognitively healthy adults with increased brain amyloidosis [13]. Higher $\omega-3$ content of red blood cells was also associated with a lower rate of hippocampal atrophy [31]. Atrophy of this brain region predicts progression to $\mathrm{AD}$ [32]. Therefore, understanding the mechanisms that influence DHA metabolism in the medial temporal cortex is of particular relevance to AD.

Higher regional $k^{*}$ among this relatively young adult population of APOE4 carriers may provide one mechanism for increased regional brain activation observed in young adult APOE4 carriers [33-35]. One report demonstrated differences in myelin structure and gray matter volume in infants carrying the APOE4 allele [36]. Although $A P O E 4$ is associated with increased risk for memory decline and $\mathrm{AD}$ in older adults, several (but not all) studies suggest a behavioral advantage in $A P O E 4$ for younger carriers [37]. For example, in some studies, APOE4 has been associated with higher IQ scores [38] and a higher education level [39]. Advantageous effects of the APOE4 allele have also been found for memoryrelated functions in young animals. Hippocampal longterm potentiation (LTP) was enhanced at a young age in APOE4 TR mice compared with APOE4 noncarrier TR mice [40]. This LTP enhancement was age-dependent and disappeared in the adult mice. Mondadori et al. found an association of APOE4 with better episodic memory compared with $A P O E 2$ and $A P O E 3$ in 340 
young, healthy persons [41]. Dennis et al. found enhanced functional connectivity of the medial temporal lobe with the posterior cingulate cortex in young adult $A P O E 4$ carriers [34]. Rusted et al. reported that the $A P O E 4$ in young adults was associated with improved attention and enhanced connectivity [35]. Filippini et al. reported increased default mode network coactivation in $A P O E 4$ carriers relative to noncarriers using restingstate functional MRI [33]. Combined, these findings suggest a state of increased brain activity decades prior to the onset of cognitive decline in APOE4 carriers. These reports support the "antagonistic pleiotropy" hypothesis in which cognitive advantages in younger adults support higher achievement and greater selection benefits, but may increase susceptibility to brain exhaustion and memory failure with age [42]. In this context, one possible interpretation of the higher $k^{*}$ is that APOE4 is associated with greater brain DHA loss and greater incorporation of DHA into the brain from plasma. These findings would suggest a beneficial response in cognitive function by increasing DHA consumption in APOE4 carriers in order to meet the greater metabolic demand for DHA in the brain. Researchers in several epidemiological studies and clinical trials have reported cognitive benefit from increasing DHA consumption in cognitively healthy APOE4 carriers [43]. This hypothesis merits additional investigation.

The study has several limitations. The sample size was small, and the study was a post hoc analysis of middleaged, predominantly white adults. We also did not have sufficient participants to examine the effect of age or separate homozygous from heterozygous APOE4 carriers. DHA incorporation into the brain may not be dependent upon transport of peripheral lipoproteins; thus, our observed differences may be due to APOE4-related differences in transport across the $\mathrm{BBB}$, intracellular transport, metabolism, or degradation processes. Unfortunately, data were not available to evaluate these hypotheses.

\section{Conclusions}

To our knowledge, this is the first study describing brain DHA incorporation coefficient in the context of the APOE4 allele and shows that brain regions implicated in the development of $\mathrm{AD}$ have different DHA incorporation coefficients, depending on $A P O E$ status. These findings support the development of novel DHA uptake imaging modalities such as $\left[{ }^{18} \mathrm{~F}\right]$-DHA to potentially accelerate the application of DHA imaging in clinical research. Knowledge of brain DHA metabolism will enhance understanding of how the $A P O E 4$ allele affects cognitive function and $\mathrm{AD}$ risk across the lifespan.

\section{Abbreviations}

AD: Alzheimer's disease; APOE: Apolipoprotein E; APOE4: Apolipoprotein E ع4; BBB: Blood-brain barrier; BMI: Body mass index; CoA: Coenzyme A; CSF: Cerebrospinal fluid; DHA: Docosahexaenoic acid; DHQ: Diet History Questionnaire; HDL-C: High-density lipoprotein cholesterol;

$J_{\text {in: }}$ Docosahexaenoic acid uptake rate; $k^{*}$ : Docosahexaenoic acid uptake coefficient; LDL-C: Low-density lipoprotein cholesterol; LTP: Long-term potentiation; MRI: Magnetic resonance imaging; PET: Positron emission tomography; PLA 2 : Phospholipase $A_{2}$; PUFA: Polyunsaturated fatty acid; PVE: Partial volume error; rCBF: Regional cerebral blood flow; ROI: Region of interest; TR: Targeted replacement

\section{Funding}

HNY was supported by grant K23HL107389 from the National Heart, Lung, and Blood Institute and grant NIRG-15-361854 from the Alzheimer's Association. SIR was supported entirely by the intramural program of the National Institute on Aging. SCC holds a university chair in brain metabolism and aging. Partial funding for SCC's contribution to this work was provided by Fonds de Recherche Santé Quebec (FRO), MITACS and the Research Center on Aging, Sherbrooke, QC, Canada. JRH and JCU and the conduct of the clinical study were supported by the intramural program of the National Institute on Alcohol Abuse and Alcoholism.

\section{Availability of supporting data}

The supporting data is available at the corresponding author and can be accessed by request.

\section{Authors' contributions}

HNY conceived of the study design by APOE genotype and designed the study analysis plan. HNY and EC analyzed the data. HNY drafted the manuscript. JCU, JRH, and SIR designed the original DHA trial. VR analyzed the APOE expression. SCC, SIR, JRH, VR, HNY, and JCU critically appraised the literature and also participated in the study design and the writing of the manuscript. SCC, JRH, and SIR critically appraised the manuscript for important intellectual content. All authors read and approved the final manuscript.

\section{Competing interests}

The authors declare that they have no competing interests.

\section{Consent for publication}

All authors have consented to publishing this work.

\section{Ethics approval and consent to participate}

The National Institute on Alcohol Abuse and Alcoholism (NIAAA) Institutional Review Board approved this study (protocol 04-AA-0058), as did the National Institutes of Health $(\mathrm{NIH})$ Radiation Safety Committee. Written informed consent was obtained from all participants, who were compensated for their participation.

\section{Author details}

'Department of Medicine, University of Southern California, 2250 Alcazar Street, Room 210, Los Angeles, CA 90033, USA. ²Research Center on Aging, University of Sherbrooke, Sherbrooke, QC, Canada. ${ }^{3}$ Section on Nutritional Neurosciences, National Institute on Alcohol Abuse and Alcoholism, National Institutes of Health, Rockville, MD, USA. ${ }^{4}$ Brain Physiology and Metabolism Section, National Institute on Aging, National Institutes of Health, Bethesda, MD, USA. ${ }^{5}$ Division of Psychiatry Products, Center for Drug Evaluation and Research, U.S. Food and Drug Administration, College Park, MD, USA.

Received: 17 January 2017 Accepted: 28 February 2017

Published online: 23 March 2017

\section{References}

1. Weisgraber KH, Innerarity TL, Mahley RW. Abnormal lipoprotein receptorbinding activity of the human $\mathrm{E}$ apoprotein due to cysteine-arginine interchange at a single site. J Biol Chem. 1982;257(5):2518-21.

2. Vitali C, Wellington $\mathrm{CL}$, Calabresi L. HDL and cholesterol handling in the brain. Cardiovasc Res. 2014;103(3):405-13.

3. Boehm-Cagan A, Bar R, Liraz O, Bielicki JK, Johansson JO, Michaelson DM. ABCA1 agonist reverses the ApoE4-driven cognitive and brain pathologies. $J$ Alzheimers Dis. 2016;54(3):1219-33. 
4. Heinsinger NM, Gachechiladze MA, Rebeck GW. Apolipoprotein E genotype affects size of ApoE complexes in cerebrospinal fluid. J Neuropathol Exp Neurol. 2016;75(10):918-24.

5. Yang Y, Keene CD, Peskind ER, Galasko DR, Hu SC, Cudaback E, et al. Cerebrospinal fluid particles in Alzheimer disease and Parkinson disease. J Neuropathol Exp Neurol. 2015;74(7):672-87.

6. Gregg RE, Zech LA, Schaefer EJ, Stark D, Wilson D, Brewer Jr HB. Abnormal in vivo metabolism of apolipoprotein E4 in humans. J Clin Invest. 1986;78(3): 815-21. Pubmed Central PMCID: 423680.

7. La L, Hansen HS, Jørgensen MH, Michaelsen KF. The essentiality of long chain $\mathrm{n}-3$ fatty acids in relation to development and function of the brain and retina. Prog Lipid Res. 2001;40(1):1-94.

8. Cao D, Kevala K, Kim J, Moon HS, Jun SB, Lovinger D, et al. Docosahexaenoic acid promotes hippocampal neuronal development and synaptic function. J Neurochem. 2009;111(2):510-21. Pubmed Central PMCID: 2773444

9. Salem Jr N, Moriguchi T, Greiner RS, McBride K, Ahmad A, Catalan JN, et al. Alterations in brain function after loss of docosahexaenoate due to dietary restriction of n-3 fatty acids. J Mol Neurosci. 2001;16(2-3):299-307. discussion 317-21.

10. Grimm MO, Kuchenbecker J, Grosgen S, Burg VK, Hundsdorfer B, Rothhaar $T L$, et al. Docosahexaenoic acid reduces amyloid $\beta$ production via multiple pleiotropic mechanisms. J Biol Chem. 2011;286(16):14028-39. Pubmed Central PMCID: 3077603

11. Hjorth E, Zhu M, Toro VC, Vedin I, Palmblad J, Cederholm T, et al. Omega-3 fatty acids enhance phagocytosis of Alzheimer's disease-related amyloid$\beta 42$ by human microglia and decrease inflammatory markers. J Alzheimers Dis. 2013;35(4):697-713.

12. Hooijmans CR, Rutters F, Dederen PJ, Gambarota G, Veltien A, van Groen T, et al. Changes in cerebral blood volume and amyloid pathology in aged Alzheimer APP/PS1 mice on a docosahexaenoic acid (DHA) diet or cholesterol enriched Typical Western Diet (TWD). Neurobiol Dis. 2007;28(1): 16-29.

13. Yassine HN, Feng Q, Azizkhanian I, Rawat V, Castor K, Fonteh AN, et al. Association of serum docosahexaenoic acid with cerebral amyloidosis. JAMA Neurol. 2016;73(10):1208-16.

14. Robinson PJ, Noronha J, DeGeorge JJ, Freed LM, Nariai T, Rapoport SI. A quantitative method for measuring regional in vivo fatty-acid incorporation into and turnover within brain phospholipids: review and critical analysis. Brain Res Brain Res Rev. 1992;17(3):187-214.

15. Lands WEM, Crawford CG. Enzymes of membrane phospholipid metabolism in animals. In: Martonosoi A, editor. The enzymes of biological membranes, Biosynthesis of cell components, vol. 2. New York: Springer; 1976. p. 3-85.

16. Chang MC, Arai T, Freed LM, Wakabayashi S, Channing MA, Dunn BB, et al. Brain incorporation of $\left[1-{ }^{11} \mathrm{C}\right]$ arachidonate in normocapnic and hypercapnic monkeys, measured with positron emission tomography. Brain Res. 1997; 755(1):74-83.

17. Contreras MA, Greiner RS, Chang MC, Myers CS, Salem Jr N, Rapoport SI. Nutritional deprivation of a-linolenic acid decreases but does not abolish turnover and availability of unacylated docosahexaenoic acid and docosahexaenoyl-CoA in rat brain. J Neurochem. 2000;75(6):2392-400.

18. Chen CT, Kitson AP, Hopperton KE, Domenichiello AF, Trepanier MO, Lin LE, et al. Plasma non-esterified docosahexaenoic acid is the major pool supplying the brain. Sci Rep. 2015;5:15791. Pubmed Central PMCID: PMC4625162.

19. Chouinard-Watkins R, Rioux-Perreault C, Fortier M, Tremblay-Mercier J, Zhang $Y$, Lawrence $\mathrm{P}$, et al. Disturbance in uniformly ${ }^{13} \mathrm{C}$-labelled DHA metabolism in elderly human subjects carrying the apoE $\varepsilon 4$ allele. $\mathrm{Br} J$ Nutr. 2013;110(10):1751-9.

20. Vandal M, Alata W, Tremblay C, Rioux-Perreault C, Salem Jr N, Calon F, et al. Reduction in DHA transport to the brain of mice expressing human APOE4 compared to APOE2. J Neurochem. 2014;129(3):516-26.

21. Yassine HN, Rawat V, Mack WJ, Quinn JF, Yurko-Mauro K, Bailey-Hall E, et al. The effect of APOE genotype on the delivery of DHA to cerebrospinal fluid in Alzheimer's disease. Alzheimers Res Ther. 2016;8:25. Pubmed Central PMCID: 4928349

22. Umhau JC, Zhou W, Thada S, Demar J, Hussein N, Bhattacharjee AK, et al. Brain docosahexaenoic acid [DHA] incorporation and blood flow are increased in chronic alcoholics: a positron emission tomography study corrected for cerebral atrophy. PLoS One. 2013:8(10):e75333. Pubmed Central PMCID: 3788756
23. Subar AF, Ziegler RG, Thompson FE, Johnson CC, Weissfeld JL, Reding D, et al. Is shorter always better? Relative importance of questionnaire length and cognitive ease on response rates and data quality for two dietary questionnaires. Am J Epidemiol. 2001:153(4):404-9.

24. Umhau JC, Zhou W, Carson RE, Rapoport SI, Polozova A, Demar J, et al. Imaging incorporation of circulating docosahexaenoic acid into the human brain using positron emission tomography. J Lipid Res. 2009;50(7):1259-68. Pubmed Central PMCID: 2694326.

25. Koska J, Yassine H, Trenchevska O, Sinari S, Schwenke DC, Yen FT, et al. Disialylated apolipoprotein C-III proteoform is associated with improved lipids in prediabetes and type 2 diabetes. J Lipid Res. 2016;57(5):894-905.

26. Cheon Y, Kim HW, Igarashi M, Modi HR, Chang L, Ma K, et al. Disturbed brain phospholipid and docosahexaenoic acid metabolism in calciumindependent phospholipase $\mathrm{A}_{2}-\mathrm{VII}$ (iPLA $\mathrm{A}_{2} \beta$ )-knockout mice. Biochim Biophys Acta. 2012;1821(9):1278-86. Pubmed Central PMCID: PMC3393806.

27. Basselin M, Rosa AO, Ramadan E, Cheon Y, Chang L, Chen M, et al. Imaging decreased brain docosahexaenoic acid metabolism and signaling in $\mathrm{PLA}_{2} \beta$ (VIA)-deficient mice. J Lipid Res. 2010;51(11):3166-73. Pubmed Central PMCID: PMC2952557.

28. Ouellet M, Emond V, Chen CT, Julien C, Bourasset F, Oddo S, et al. Diffusion of docosahexaenoic and eicosapentaenoic acids through the blood-brain barrier: an in situ cerebral perfusion study. Neurochem Int. 2009:55(7):476-82.

29. Giovacchini G, Lerner A, Toczek MT, Fraser C, Ma K, DeMar JC, et al. Brain incorporation of ${ }^{11} \mathrm{C}$-arachidonic acid, blood volume, and blood flow in healthy aging: a study with partial-volume correction. J Nucl Med. 2004;45(9):1471-9.

30. Giovacchini G, Chang MC, Channing MA, Toczek M, Mason A, Bokde AL, et al. Brain incorporation of $\left[{ }^{[1} \mathrm{C}\right]$ arachidonic acid in young healthy humans measured with positron emission tomography. J Cereb Blood Flow Metab. 2002;22(12):1453-62

31. Pottala JV, Yaffe K, Robinson JG, Espeland MA, Wallace R, Harris WS. Higher RBC EPA + DHA corresponds with larger total brain and hippocampal volumes: WHIMS-MRI study. Neurology. 2014;82(5):435-42. Pubmed Central PMCID: PMC3917688.

32. Bailey HR, Zacks JM, Hambrick DZ, Zacks RT, Head D, Kurby CA, et al. Medial temporal lobe volume predicts elders' everyday memory. Psychol Sci. 2013; 24(7):1113-22. Pubmed Central PMCID: PMC3936320

33. Filippini N, Maclntosh BJ, Hough MG, Goodwin GM, Frisoni GB, Smith SM, et al. Distinct patterns of brain activity in young carriers of the APOE- $\varepsilon 4$ allele. Proc Natl Acad Sci U S A. 2009;106(17):7209-14.

34. Dennis NA, Browndyke JN, Stokes J, Need A, Burke JR, Welsh-Bohmer KA, et al. Temporal lobe functional activity and connectivity in young adult APOE ع4 carriers. Alzheimers Dement. 2010;6(4):303-11.

35. Rusted J, Evans S, King S, Dowell N, Tabet N, Tofts P. APOE $\varepsilon 4$ polymorphism in young adults is associated with improved attention and indexed by distinct neural signatures. Neuroimage. 2013;65:364-73.

36. Dean 3rd DC, Jerskey BA, Chen K, Protas H, Thiyyagura P, Roontiva A, et al. Brain differences in infants at differential genetic risk for late-onset Alzheimer disease: a cross-sectional imaging study. JAMA Neurol. 2014;71(1): 11-22. Pubmed Central PMCID: PMC4056558.

37. Tuminello ER, Han SD. The apolipoprotein e antagonistic pleiotropy hypothesis: review and recommendations. Int J Alzheimers Dis. 2011;2011: 726197. Pubmed Central PMCID: 3056453

38. Yu YWY, Lin CH, Chen SP, Hong CJ, Tsai SJ. Intelligence and event-related potentials for young female human volunteer apolipoprotein $E \varepsilon 4$ and non$\varepsilon 4$ carriers. Neurosci Lett. 2000;294(3):179-81.

39. Hubacek JA, Pitha J, Škodová Z, Adamkova V, Lánská V, Poledne R. A possible role of apolipoprotein $\mathrm{E}$ polymorphism in predisposition to higher education. Neuropsychobiology. 2001;43(3):200-3.

40. Kitamura HW, Hamanaka H, Watanabe M, Wada K, Yamazaki C, Fuijta SC, et al. Age-dependent enhancement of hippocampal long-term potentiation in knock-in mice expressing human apolipoprotein E4 instead of mouse apolipoprotein E. Neurosci Lett. 2004;369(3):173-8.

41. Mondadori CR, Dominique JF, Buchmann A, Mustovic $\mathrm{H}$, Wollmer MA Schmidt CF, et al. Better memory and neural efficiency in young apolipoprotein E $\varepsilon 4$ carriers. Cereb Cortex. 2007;17(8):1934-47.

42. Han SD, Bondi MW. Revision of the apolipoprotein E compensatory mechanism recruitment hypothesis. Alzheimers Dement. 2008;4(4):251-4.

43. Yassine HN, Braskie MN, Mack WJ, Castor KJ, Fonteh AN, Schneider LS, et al. Association of docosahexaenoic acid supplementation with Alzheimer disease stage in apolipoprotein E $\varepsilon 4$ carriers: a review. JAMA Neurol. 2017; 74(3):339-47. 